\title{
Eldecalcitol reduces the risk of severe vertebral fractures and improves the health-related quality of life in patients with osteoporosis
}

\author{
Hiroshi Hagino • Toshiyuki Takano • \\ Masao Fukunaga $\cdot$ Masataka Shiraki • \\ Toshitaka Nakamura $\cdot$ Toshio Matsumoto
}

Received: 30 August 2012/ Accepted: 1 October 2012/Published online: 6 November 2012

(C) The Japanese Society for Bone and Mineral Research and Springer Japan 2012

\begin{abstract}
Eldecalcitol reduces the risk of vertebral fractures in comparison to alfacalcidol in osteoporotic patients under vitamin $\mathrm{D}$ repletion. The aim of this study was to evaluate the effects of eldecalcitol on the spinal location of incident vertebral fractures, the severity of the fractures, and the changes in health-related quality of life (HRQOL) compared with those of alfacalcidol. The post hoc analysis has been performed on the data from the three-year, double-blind, randomized, head-to-head clinical trial of eldecalcitol versus alfacalcidol conducted in Japan. A total of 1054 patients were enrolled and randomized to take $0.75 \mu \mathrm{g}$ eldecalcitol or $1.0 \mu \mathrm{g}$ alfacalcidol daily for 3 years. The incidence of vertebral fractures was re-evaluated based on the location on the spine (upper T4-T10; lower T11-L4). The severity of vertebral fractures was determined by the semi-quantitative method, and the
\end{abstract}

H. Hagino $(\bowtie)$

School of Health Science, Tottori University, 86 Nishi-Cho,

Yonago, Tottori 683-8503, Japan

e-mail: hagino@med.tottori-u.ac.jp

T. Takano

Chugai Pharmaceutical Co. Ltd, Tokyo 103-8324, Japan

M. Fukunaga

Kawasaki Medical School, Okayama 701-0192, Japan

M. Shiraki

Research Institute and Practice for Involutional Diseases,

Nagano 399-8101, Japan

T. Nakamura

University of Occupational and Environmental Health,

Fukuoka 807-8555, Japan

T. Matsumoto

University of Tokushima Graduate School of Medical Sciences,

Tokushima 770-8503, Japan change in HRQOL was analyzed by using the Medical Outcomes Study Short Form 36-item questionnaire. The incidence of vertebral fracture at the lower spine was less in the eldecalcitol group than in the alfacalcidol group $(p=0.029)$. The incidence of severe vertebral fracture (Grade 3) was $3.8 \%$ in the eldecalcitol group and $6.7 \%$ in the alfacalcidol group, demonstrated a significant difference between the 2 groups $(p=0.036)$. Both eldecalcitol and alfacalcidol improved HRQOL in osteoporotic patients. Although no significant differences in each HRQOL scores were observed between eldecalcitol and alfacalcidol during the observational period, overall improvement from baseline of HRQOL scores were clearly observed in the eldecalcitol group. In conclusion, the incidences of lower spinal vertebral fractures and severe vertebral fractures were reduced further by eldecalcitol compared to alfacalcidol in the 3-year clinical trial. Daily treatment with eldecalcitol is effective in improving HRQOL, possibly owing to the reduced risk of lower spinal vertebral fractures and/or severe vertebral fractures.

Keywords Eldecalcitol - Health-related quality of life . Osteoporosis · Vertebral fracture

\section{Introduction}

With the rapid increase in the elderly population, osteoporosis and osteoporosis-related fractures have become major concerns in many countries. In patients with a high fracture risk, appropriate treatment is needed with drugs that have shown definite evidence of their fracture prevention effect. Postmenopausal osteoporosis is induced by accelerated bone resorption and a systemic calcium imbalance due to estrogen deficiency induced by menopause. 
Moreover, deficiency or insufficiency of vitamin D seems a common health problem in elderly people, especially in patients with fragility fractures [1]. Active vitamin D, calcitriol, and its prodrug alfacalcidol are widely used in the treatment of calcium- and bone-related diseases including osteoporosis. Several studies have examined their effects on the incidence of fragility fractures in osteoporotic patients, and some studies demonstrated that treatment with calcitriol or alfacalcidol resulted in a significant reduction in incidence of vertebral fractures compared with control [2-4].

Eldecalcitol, a vitamin $\mathrm{D}$ analog that has a hydroxy-

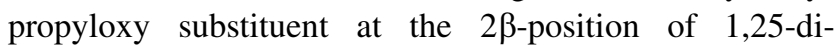
hydroxyvitamin $\mathrm{D}_{3}$, is available in Japan for the treatment of osteoporosis at a dosage of $0.75 \mu \mathrm{g} /$ day. In a randomized, double-blind comparison with alfacalcidol ( $1.0 \mu \mathrm{g} /$ day $)$, eldecalcitol $(0.75 \mu \mathrm{g} /$ day $)$ produced significantly greater reductions in biomarkers of both bone formation and bone resorption among vitamin-D-sufficient osteoporotic patients [5]. In that trial, eldecalcitol treatment was associated with an increase in bone mineral density and had a positive effect on femoral biomechanical properties, showing significant differences from the patients who received alfacalcidol [6]. Concerning fracture prevention, in comparison with alfacalcidol, eldecalcitol significantly reduced the 3-year incidence of vertebral fractures, with an absolute risk reduction of $4.1 \%$ over this period, representing a relative risk reduction of $26 \%$. No significant difference in the incidence of total non-vertebral fractures was observed between the eldecalcitol and alfacalcidol groups; however, the incidence of fractures in the alfacalcidol group at 36 months tended to be lower at the 3 major nonvertebral sites (humerus, wrist, and hip).

Fracture prevention is the main aim in the treatment of osteoporosis; however, health-related quality of life (HRQOL) is also an important consideration in its management. The morbidity of vertebral fractures in patients with osteoporosis varies from mild cases, with only slight pain, to severe and multiple fracture cases with acute pain and many recurrences, and this depends on the location of the vertebral fracture on the spine. It is reported that there is a difference in HRQOL of patients depending on the spinal location of the vertebral fracture [7, 8]. Therefore, the location of the vertebral fracture is an important factor relating to the impairment of HRQOL. However to the best of our knowledge, there is no report on the effect of antiosteoporosis drugs with respect to the vertebral fracture location and its relation to HRQOL. Accordingly, the purpose of the present study was to evaluate the effects of eldecalcitol versus alfacalcidol on the location of incident vertebral fractures and on the severity of the fractures, as well as the changes in HRQOL in each group.

\section{Materials and methods}

\section{Study design}

This was a post hoc analysis of a 3-year, phase III, randomized, active comparator, double-blind, head-to-head trial of the effect of eldecalcitol versus alfacalcidol on reduction in incidence of vertebral fractures. Details of the design and the results of the primary endpoint in the study have been published previously [5]. In that phase III trial, the primary endpoint was the incidence of non-traumatic new vertebral fractures, while other endpoints were the percent change in lumbar spine BMD and total hip BMD, percent change in bone turnover markers, and incidence of non-vertebral fractures. In the current study we re-assessed the incidence of vertebral fractures based on their location on the spine. We also analyzed the change in HRQOL during the 3-year observational period.

\section{Patients}

A total of 1054 patients (1030 females and 24 males, all Japanese) aged from 46 to 92 years (mean 72.1 years) from 52 centers in Japan were enrolled from September 2004 to August 2005. Patients were randomized to take $0.75 \mu \mathrm{g}$ eldecalcitol or $1.0 \mu \mathrm{g}$ alfacalcidol once a day for 3 years (36 months) [5]. Patients with serum 25(OH)D values lower than $20 \mathrm{ng} / \mathrm{mL}$ at baseline were given an oral vitamin $\mathrm{D}_{3}$ supplement (400 IU) once a day. Patients with lumbar spine or total hip BMD T-score below -1.7 were enrolled if they had 1 to 5 vertebral fractures. Patients without vertebral fractures were also enrolled if their lumbar spine or total hip BMD T-score was below -2.6 and they were aged 70 years or older, or if their T-score was below -3.4 and they were aged less than 70 years. Patients with metabolic bone disease such as primary hyperparathyroidism, Cushing's syndrome, premature menopause, poorly controlled diabetes mellitus (HbA1c over $9 \%$ ), or other causes of secondary osteoporosis or patients who had a history of urolithiasis were excluded from the study. Patients were also excluded if they had taken any oral bisphosphonates within 6 months before entry or for more than 2 weeks during the period 6 to 12 months before entry, or intravenous bisphosphonates at any time; had taken glucocorticoids, calcitonin, vitamin K2, active vitamin D compounds, raloxifene, or hormone replacement therapy within 2 months; had serum calcium levels of above $10.4 \mathrm{mg} / \mathrm{dL}$ or urinary calcium excretion of over $0.4 \mathrm{mg} / \mathrm{dL}$ GF; or had serum creatinine above $1.3 \mathrm{mg} / \mathrm{dL}$.

Fracture assessment

The incidence of non-traumatic new vertebral fractures was evaluated by using lateral radiographs of the thoracic and 
lumbar spine obtained at baseline and at $6,12,24$, and 36 months after initiation of drug administration [5]. At the central facility, 3 experts independently assessed the radiographs for fractures of 13 vertebral bodies from $\mathrm{T} 4$ to L4. According to the method developed by Genant et al., prevalent vertebral fractures were semi-quantitatively classified from Grade 0 to Grade 3, respectively named as normal, mild, moderate, and severe [9]. Incident vertebral fractures were diagnosed quantitatively if the anterior, posterior, or middle vertebral height had decreased by at least $15 \%$ and by $\geq 4 \mathrm{~mm}$ in a vertebra [10] that was assessed at baseline as Grade 0,1 , or 2 . If the investigators' assessments disagreed, the final assessment was made after conference by all the investigators.

\section{Assessment of QOL}

Health-related quality of life (HRQOL) assessment of the patients was carried out by using the Medical Outcomes Study Short Form 36-item questionnaire (SF-36). SF-36 comprises 36 items, with 2-6 response options on an ordinal scale, assessing 8 health concepts or domains: physical functioning (PF), role limitations due to physical health problems (RP), bodily pain (BP), general health (GH), vitality (VT), social functioning (SF), role limitations due to emotional problems (RE), and mental health (MH) [11]. Each domain allows a score of $0-100$, with a higher score indicating better HRQOL. The assessment was performed at baseline and at 12, 24, and 36 months, and we analyzed the change in HRQOL scores from those at baseline.

\section{Statistical analysis}

We classified each prevalent vertebral fracture by its location on the spine and by the severity of the fracture (Grade $0-3)$ using the safety analysis set $(n=1054)$. Then, we compared the 2 treatment groups in the efficacy analysis set (eldecalcitol group: $n=526$; alfacalcidol group: $n=523$ ) with respect to the spinal location of new vertebral fractures, changes in the severity of vertebral fractures, the incidence of upper (T4-T10)/lower (T11-L4) vertebral fractures [12], and the incidence of severe vertebral fractures. Here, the incidences of severe vertebral fractures were calculated based on the number of patients with incident vertebral fractures from normal to severe, mild to severe, and moderate to severe fractures.

Analyses of upper/lower vertebral fracture incidences were performed by Poisson regression with the number of prevalent vertebral fractures at baseline as the covariate (categories: no fracture, 1 fracture, $>1$ fracture). The incidence of severe vertebral fractures was calculated by Kaplan-Meier estimates at times when radiography was performed. To compare eldecalcitol to alfacalcidol for the incidence of severe vertebral fractures, stratified log-rank tests (2-sided, $5 \%$ significance level) were performed, and stratified Cox regression models were used to determine the hazard ratios and the $95 \%$ confidence intervals, with adjustment for the number of prevalent vertebral fractures at baseline (categories: no fracture, 1 fracture, $>1$ fracture).

The changes in HRQOL scores from baseline were evaluated by paired $t$ tests for each group, and the intergroup differences were evaluated by non-paired $t$ tests.

Differences were considered to be statistically significant if the $p$ value was less than 0.05 .

\section{Results}

Patient characteristics

There were no significant differences at baseline between the eldecalcitol and the alfacalcidol groups with respect to age, gender, number of patients with vitamin D supplementation, prevalence of vertebral fractures, or HRQOL scores (Table 1). Numbers of patients with prevalent vertebral fractures of Grade 1, Grade 2, and Grade 3 were 111 $(21.0 \%), 132(25.0 \%)$, and $86(16.3 \%)$ in eldecalcitol group, $120(22.8 \%), 102(19.4 \%)$, and $110(20.9 \%)$ in alfacalcidol group, respectively.

\section{Incidence of vertebral fractures}

The prevalent vertebral fractures at baseline and the new vertebral fractures during the study by spinal location are shown in Fig. 1. At baseline there were 2 peaks, at T6-T8 and at $\mathrm{T} 11-\mathrm{L} 1$, in the distribution of prevalent vertebral fractures in all patients. During the 3-year treatment new vertebral fractures showed a single peak in the distribution at T12-L1 in both groups. The incidence of lower vertebral fractures was lower in the eldecalcitol group than in the alfacalcidol group ( $p=0.029)$ (Fig. 2).

Changes in the maximum grade of vertebral fracture from pre-treatment grade to grade at final follow-up among the patients with new vertebral fractures during the study are shown in Table 2 by pre-treatment grade. In both groups, the number of patients whose baseline fracture grade of normal increased to a final fracture grade of mild was similar in both the eldecalcitol and the alfacalcidol groups, as was the number of patients whose baseline fracture grade of normal or mild increased to a final fracture grade of moderate; however, the incidence of severe vertebral fractures seemed to be lower in the eldecalcitol group than in the alfacalcidol group. The cumulative incidence of severe vertebral fractures (Grade 3 ) over the 3 years was $3.8 \%$ in the eldecalcitol group and $6.7 \%$ in 
Table 1 Baseline characteristics of enrolled patients
Data are means (SD)

There were no significant differences at baseline characteristics between the eldecalcitol and the alfacalcidol groups

Some of the data in this table has been reported previously [5]

Fig. 1 Prevalence of vertebral fractures at baseline (a), incidence of vertebral fractures during the study by spinal location in eldecalcitol group and alfacalcidol group (b)

\begin{tabular}{lcc}
\hline & Eldecalcitol $(n=528)$ & Alfacalcidol $(n=526)$ \\
\hline Age (years) & $72.2(6.60)$ & $72.1(6.64)$ \\
Male patients $[n(\%)]$ & $9(1.70)$ & $15(2.85)$ \\
Patients with vitamin D supplementation $[n(\%)]$ & $208(39.4)$ & $206(39.2)$ \\
Number of prevalent vertebral fractures & $1.18(1.28)$ & $1.25(1.36)$ \\
Without fracture $[n(\%)]$ & $199(37.7)$ & $194(36.9)$ \\
With 1 fracture $[n(\%)]$ & $156(29.5)$ & $160(30.4)$ \\
With 2 or more fractures $[n(\%)]$ & $173(32.8)$ & $172(32.7)$ \\
Maximum grade of prevalent vertebral fracture & & \\
Grade 0 (normal) $[n(\%)]$ & $199(37.7)$ & $194(36.9)$ \\
Grade 1 (mild) $[n(\%)]$ & $111(21.0)$ & $120(22.8)$ \\
Grade 2 (moderate) $[n(\%)]$ & $132(25.0)$ & $102(19.4)$ \\
Grade 3 (severe) $[n(\%)]$ & $86(16.3)$ & $110(20.9)$ \\
HRQOL score & & \\
Physical functioning & $74.4(20.7)$ & $75.2(20.0)$ \\
Role-physical & $74.8(25.6)$ & $76.5(25.2)$ \\
Bodily pain & $61.0(24.3)$ & $61.7(23.6)$ \\
General health & $61.2(18.1)$ & $61.5(18.8)$ \\
Vitality & $62.8(20.6)$ & $64.2(20.5)$ \\
Social functioning & $84.0(22.1)$ & $85.0(19.6)$ \\
Role-emotional & $78.1(24.9)$ & $81.8(23.9)$ \\
Mental health & $72.2(20.7)$ & $74.0(19.2)$ \\
\hline
\end{tabular}

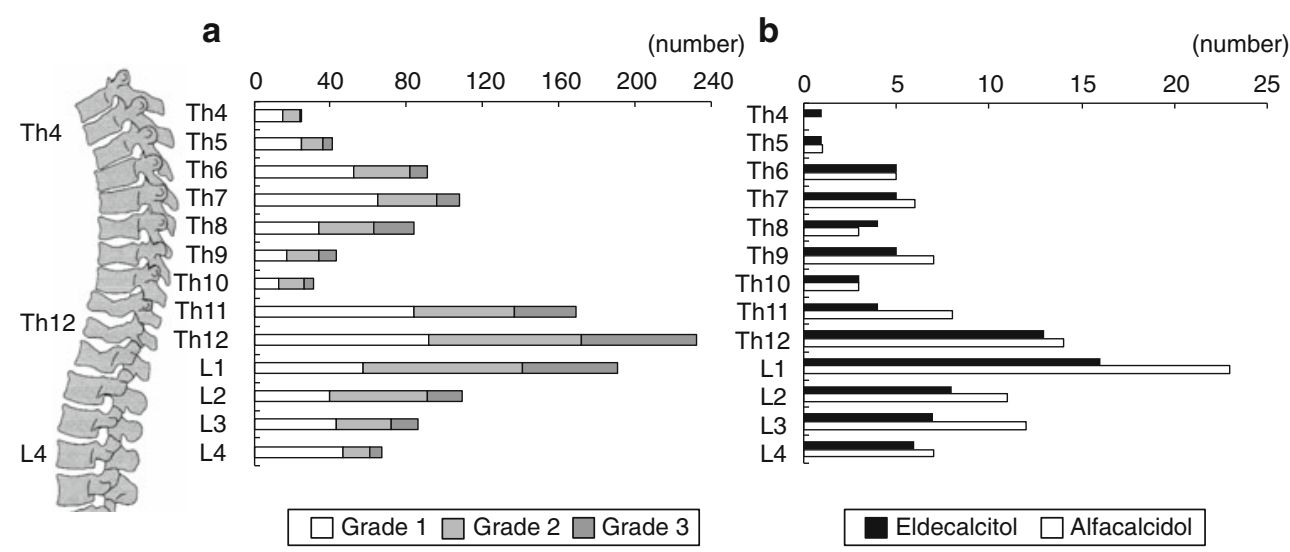

the alfacalcidol group by Kaplan-Meier estimates, showing a significant difference between the 2 groups (hazard ratio, 0.53 ; $95 \%$ CI 0.29-0.96, $p=0.036$ ) (Fig. 3).

\section{QOL}

Assessment of HRQOL in all domains tended to be better in the eldecalcitol group than in the alfacalcidol group throughout the study period (Fig. 4). Eldecalcitol significantly improved HRQOL scores in the domains of PF, RP, $\mathrm{BP}$, and VT at 12 months and in BP at 36 months compared with their baseline values. On the other hand, alfacalcidol significantly improved PF and BP at 12 months and $\mathrm{BP}$ at 36 months compared with their baseline values; however, PF became significantly worse at 36 months. Although no significant differences in each HRQOL scores were observed between eldecalcitol and alfacalcidol during the observational period, overall improvement from baseline of HRQOL scores were clearly observed in the eldecalcitol group.

\section{Discussion}

Vertebral fractures are the most common of all osteoporotic fractures, and are linked to impaired mobility and increased mortality [13, 14]. The current study re-evaluated the phase III trial of eldecalcitol and tried to elucidate 


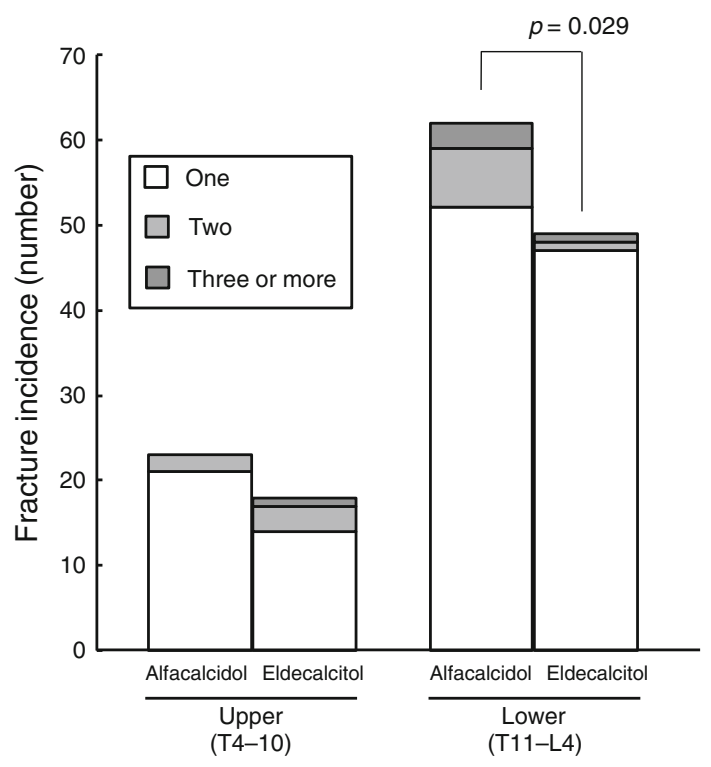

Fig. 2 Incidence of new vertebral fractures in specific locations. The colors of the bar indicate number of vertebral fractures present simultaneously

the effects of eldecalcitol on fracture prevention in comparison with alfacalcidol, subdividing the subjects based on the spinal location and severity of vertebral fractures. It was demonstrated that the incidences of lower vertebral fractures as well as severe fractures were lower in the eldecalcitol group than in the alfacalcidol group. Preventing severe vertebral fractures is clinically worthwhile, since an increase in severity of prevalent vertebral fractures increases the risk for both new vertebral fractures and new moderate or severe vertebral fractures $[15,16]$.

Several studies have investigated the impact of prevalent or incident vertebral fractures on HRQOL and found that they have an adverse impact on HRQOL regardless of symptomatology [7, 14, 17]. A progressive worsening

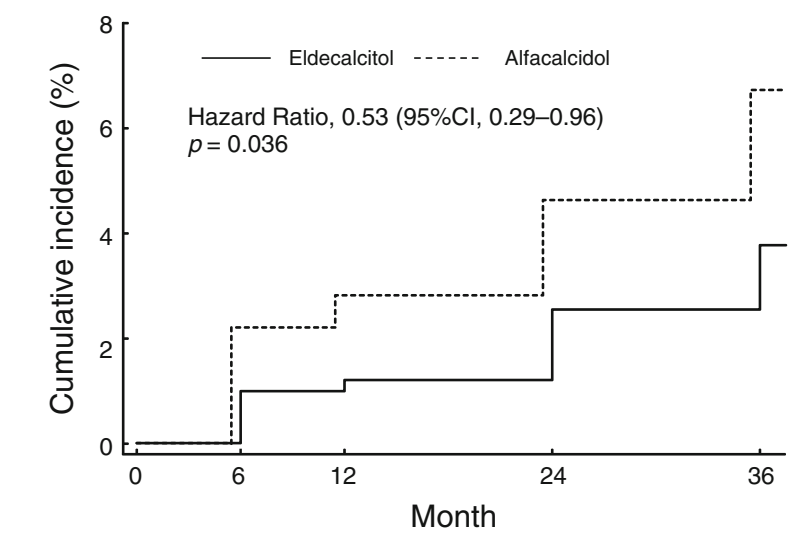

No. at risk

Eldecalcitol $526 \quad 498 \quad 478$

Alfacalcidol $523 \quad 488 \quad 465$

438

421

389

Fig. 3 Incidence of new severe vertebral fractures. The incidence of severe vertebral fractures (Grade 3 ) over 3 years was $3.8 \%$ in the eldecalcitol group and $6.7 \%$ in the alfacalcidol group by KaplanMeier estimates, showing a significant difference

trend in HRQOL with an increasing number of prevalent fractures has been observed $[18,19]$. HRQOL as evaluated by SF-36 in patients with vertebral fractures at 7-year follow-up was found to be reduced further than in the hip fracture group in the domains of BP, VT, RE, and MH after controlling for age, new fractures, and new co-morbidity [14]. Based on these studies it was concluded that pain and disability after vertebral fracture do not fade away unless effective treatment is given [14, 20,21].

Improvement of HRQOL in patients with osteoporosis has been reported following pharmaceutical treatment with alendronate [22, 23], risedronate [24], elcatonin [25], and teriparatide [26]. In those studies, HRQOL improved significantly with alendronate or risedronate treatment as compared with the active control. In the current study, we

Table 2 Severity of new vertebral fractures

\begin{tabular}{|c|c|c|c|c|c|c|c|c|}
\hline \multirow[t]{3}{*}{ Pre-treatment grade } & \multicolumn{3}{|c|}{ (A) Eldecalcitol } & \multirow[t]{3}{*}{ Total } & \multicolumn{3}{|c|}{ (B) Alfacalcidol } & \multirow[t]{3}{*}{ Total } \\
\hline & \multicolumn{3}{|c|}{ Final fracture grade } & & \multicolumn{3}{|c|}{ Final fracture grade } & \\
\hline & Mild & Moderate & Severe & & Mild & Moderate & Severe & \\
\hline Normal (Grade 0) & $\begin{array}{l}17 \\
(26.6 \%)\end{array}$ & $\begin{array}{l}24 \\
(37.5 \%)\end{array}$ & $\begin{array}{l}11 \\
(17.2 \%)\end{array}$ & $\begin{array}{l}52 \\
(81.3 \%)\end{array}$ & $\begin{array}{l}17 \\
(21.3 \%)\end{array}$ & $\begin{array}{l}31 \\
(38.8 \%)\end{array}$ & $\begin{array}{l}19 \\
(23.8 \%)\end{array}$ & $\begin{array}{l}67 \\
(83.8 \%)\end{array}$ \\
\hline Mild (Grade 1) & - & $\begin{array}{l}5 \\
(7.8 \%)\end{array}$ & $\begin{array}{l}0 \\
(0.0 \%)\end{array}$ & $\begin{array}{l}5 \\
(7.8 \%)\end{array}$ & - & $\begin{array}{l}2 \\
(2.5 \%)\end{array}$ & $\begin{array}{l}2 \\
(2.5 \%)\end{array}$ & $\begin{array}{l}4 \\
(5.0 \%)\end{array}$ \\
\hline Moderate (Grade 2) & - & $\begin{array}{l}1^{\mathrm{a}} \\
(1.6 \%)\end{array}$ & $\begin{array}{l}6 \\
(9.4 \%)\end{array}$ & $\begin{array}{l}7 \\
(10.9 \%)\end{array}$ & $\begin{array}{l}- \\
-\end{array}$ & $\begin{array}{l}- \\
-\end{array}$ & $\begin{array}{l}9 \\
(11.3 \%)\end{array}$ & $\begin{array}{l}9 \\
(11.3 \%)\end{array}$ \\
\hline Total & $\begin{array}{l}17 \\
(26.6 \%)\end{array}$ & $\begin{array}{l}30 \\
(46.9 \%)\end{array}$ & $\begin{array}{l}17 \\
(26.6 \%)\end{array}$ & $\begin{array}{l}64 \\
(100 \%)\end{array}$ & $\begin{array}{l}17 \\
(21.3 \%)\end{array}$ & $\begin{array}{l}33 \\
(41.3 \%)\end{array}$ & $\begin{array}{l}30 \\
(37.5 \%)\end{array}$ & $\begin{array}{l}80 \\
(100 \%)\end{array}$ \\
\hline
\end{tabular}

Data are number of patients

${ }^{\text {a }}$ A patient with incident fracture with vertebral height reduction of $15 \%$ and $\geq 4 \mathrm{~mm}$ but without grade change 


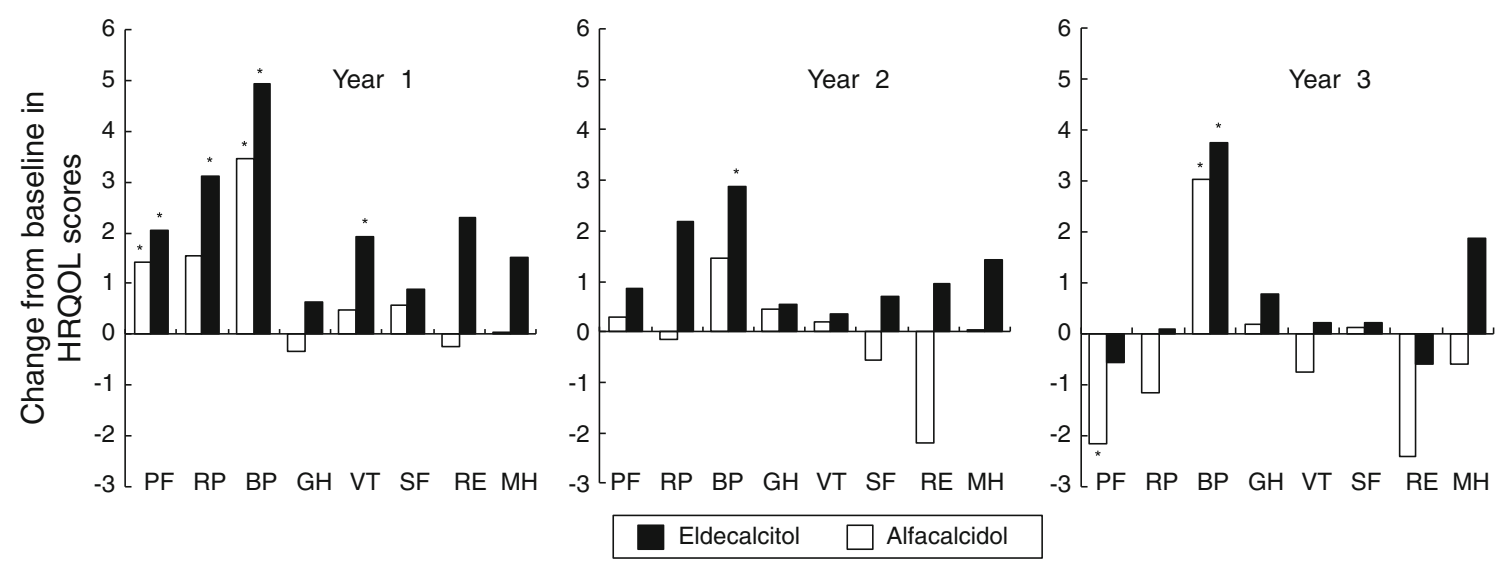

Fig. 4 Changes from baseline in HRQOL scores as evaluated by SF36. *Significantly different from baseline $(p<0.05)$. $P F$ physical functioning, $R P$ role limitations due to physical health problems, $B P$ bodily pain, $G H$ general health, $V T$ vitality, $S F$ social functioning, $R E$ role limitations due to emotional problems, $M H$ mental health assessed HRQOL for the first time in a trial of active vita$\min \mathrm{D}_{3}$ in Japanese patients with osteoporosis. Our results clearly demonstrated an improvement in HRQOL after treatment with either eldecalcitol or alfacalcidol; however, greater improvement was observed in the eldecalcitol group. The impact of prevalent or incident vertebral fractures is dependent on the spinal location and fractures in the lumbar region have the most severe consequences [18]. Significant differences in HRQOL between patients with thoracic and lumbar fractures have been reported in previous studies $[8,18,19]$. In comparison to thoracic fractures, lumbar fractures had significantly stronger impact on the HRQOL domains of physical activity, general health perception, and on total scores [18]. This difference occurs because lumbar fractures are more often symptomatic than thoracic fractures, due to stabilization of the thoracic spine by the rib cage. It was reported that for patients with vertebral fractures without symptoms, changes in HRQOL score were intermediate between those for patients with symptomatic vertebral fractures and those for patients without incident vertebral fractures [18]. The improvement in HRQOL achieved in this study by eldecalcitol is partially owing to the higher preventive effects of eldecalcitol on vertebral fractures especially in the lower part of the spine (T11-L4). This also explains why bodily pain was improved most among the SF-36 domains during the observational period. Because lumbar kyphosis is thought to be related to weakness of the spinal extensors, whole kyphosis usually forces the patient to use a cane while standing and walking, resulting in a significant reduction in HRQOL compared with other postural deformities [8].

This study has several limitations. Firstly, the present study lacked a placebo group. The protocol was planned without a placebo group from the ethical point of view. Secondly, we evaluated incident vertebral fractures by morphometric assessment, and included both symptomatic and asymptomatic patients. This might have affected the HRQOL scores; however, since baseline characteristics for both groups showed no difference, its influence is limited and would not affect the results.

In conclusion, the incidences of lower spinal vertebral fractures and severe vertebral fractures were reduced further by eldecalcitol compared to alfacalcidol in the 3-year phase III clinical trial. Daily treatment with $0.75 \mu \mathrm{g}$ eldecalcitol for 3 years is effective in improving HRQOL, possibly owing to the reduced risk of lower spinal vertebral fractures or severe vertebral fractures.

Acknowledgments The present study was sponsored by Chugai Pharmaceutical Co., Ltd. The sponsor of the study participated in the design of the study, data collection, data analyses, data interpretation, and writing of the report. The sponsor supplied the study medication and had responsibility for data collection and quality control. The corresponding author had full access to all the data in the study and had responsibility for the decision to submit for publication. The authors thank all the investigators who participated in the eldecalcitol phase III clinical trial.

Conflict of interest $H$. Hagino is a member of an advisory board (Asahi Kasei Pharma, Eli Lilly, Japan) and has received research grants and/or consulting fees (Asahi Kasei Pharma, Astellas, Chugai, Eisai, Eli Lilly, Japan, Mitsubishi Tanabe Pharma, MSD, Ono, Pfizer Japan, Taisho Toyama, Takeda, Teijin Pharma). T. Takano is a fulltime employee of Chugai Pharmaceutical Co., Ltd. M. Fukunaga is a member of an advisory council (Asahi Kasei Pharma, Astellas). M. Shiraki has received consulting fees (Asahi Kasei Pharma, Astellas, Chugai, Daiichi Sankyo, MSD, Teijin Pharma) and lecture fees (Eisai, Ono). T. Nakamura has received research grants and/or consulting fees (Asahi Kasei Pharma, Astellas, Chugai, Daiichi Sankyo, Eisai, Eli Lilly Japan, MSD, Ono, Takeda, Teijin Pharma) and belongs to the Japan Ministry of Health, Welfare and Labor as a councilor for hospital administration and social medical insurance. T. Matsumoto is a member of an advisory board (Lilly) and has received consulting fees (Asahi Kasei Pharma, Astellas, Chugai, Daiichi Sankyo, Ono, Teijin Pharma). 


\section{References}

1. Sakuma M, Endo N, Hagino H, Harada A, Matsui Y, Nakano T, Nakamura K (2011) Serum 25-hydroxyvitamin D status in hip and spine-fracture patients in Japan. J Orthop Sci 16:418-423

2. Papadimitropoulos E, Wells G, Shea B, Gillespie W, Weaver B, Zytaruk N, Cranney A, Adachi J, Tuqwell P, Josse R, Greenwood C, Guyatt G (2002) Meta-analyses of therapies for postmenopausal osteoporosis. VIII: meta-analysis of the efficacy of vitamin $\mathrm{D}$ treatment in preventing osteoporosis in postmenopausal women. Endocr Rev 23:560-569

3. Tilyard MW, Spears GF, Thomson J, Dovey S (1992) Treatment of postmenopausal osteoporosis with calcitriol or calcium. N Engl J Med 326:357-362

4. O'Donnell S, Moher D, Thomas K, Hanley DA, Cranney A (2008) Systematic review of the benefits and harms of calcitriol and alfacalcidol for fractures and falls. J Bone Miner Metab 26:531-542

5. Matsumoto T, Ito M, Hayashi $Y$, Hirota T, Tanigawara $Y$, Sone T, Fukunaga M, Shiraki M, Nakamura T (2011) A new active vitamin D3 analog, eldecalcitol, prevents the risk of osteoporotic fractures - a randomized, active comparator, double-blind study. Bone 49:605-612

6. Ito M, Nakamura $T$, Fukunaga M, Shiraki M, Matsumoto T (2011) Effect of eldecalcitol, an active vitamin D analog, on hip structure and biomechanical properties: 3D assessment by clinical CT. Bone 49:328-334

7. Oleksik AM, Ewing S, Shen W, van Schoor NM, Lips P (2005) Impact of incident vertebral fractures on health related quality of life (HRQOL) in postmenopausal women with prevalent vertebral fractures. Osteoporos Int 16:861-870

8. Miyakoshi N, Itoi E, Kobayashi M, Kodama H (2003) Impact of postural deformities and spinal mobility on quality of life in postmenopausal osteoporosis. Osteoporos Int 14:1007-1012

9. Genant HK, Wu CY, van Kuijk C, Nevitt MC (1993) Vertebral fracture assessment using a semiquantitative technique. J Bone Miner Res 8:1137-1148

10. Fukunaga M, Nakamura T, Shiraki M, Kuroda T, Ohta H, Hosoi T, Orimo H (2004) Absolute height reduction and percent height ratio of the vertebral body in incident fracture in Japanese women. J Bone Miner Metab 22:104-110

11. Fukuhara S, Suzukamo Y (2004) Manual of SF-36v2 Japanese version. Institute for Health Outcomes \& Process Evaluation Research, Kyoto

12. Nevitt MC, Ross PD, Palermo L, Musliner T, Genant HK, Thompson DE (1999) Association of prevalent vertebral fractures, bone density, and alendronate treatment with incident vertebral fractures: effect of number and spinal location of fractures. The Fracture Intervention Trial Research Group. Bone 25:613-619

13. Kado DM, Duong T, Stone KL, Ensrud KE, Nevitt MC, Greendale GA, Cummings SR (2003) Incident vertebral fractures and mortality in older women: a prospective study. Osteoporos Int 14:589-594

14. Hallberg I, Bachrach-Lindstrom M, Hammerby S, Toss G, Ek AC (2009) Health-related quality of life after vertebral or hip fracture: a seven-year follow-up study. BMC Musculoskelet Disord 10:135

15. Gallagher JC, Genant HK, Crans GG, Vargas SJ, Krege JH (2005) Teriparatide reduces the fracture risk associated with increasing number and severity of osteoporotic fractures. J Clin Endocrinol Metab 90:1583-1587

16. Delmas PD, Genant HK, Crans GG, Stock JL, Wong M, Siris E, Adachi JD (2003) Severity of prevalent vertebral fractures and the risk of subsequent vertebral and nonvertebral fractures: results from the MORE trial. Bone 33:522-532

17. Silverman SL, Minshall ME, Shen W, Harper KD, Xie S (2001) The relationship of health-related quality of life to prevalent and incident vertebral fractures in postmenopausal women with osteoporosis: results from the Multiple Outcomes of Raloxifene Evaluation Study. Arthr Rheum 44:2611-2619

18. Oleksik A, Lips P, Dawson A, Minshall ME, Shen W, Cooper C, Kanis J (2000) Health-related quality of life in postmenopausal women with low BMD with or without prevalent vertebral fractures. J Bone Miner Res 15:1384-1392

19. Hagino H, Nakamura T, Fujiwara S, Oeki M, Okano T, Teshima $R$ (2009) Sequential change in quality of life for patients with incident clinical fractures: a prospective study. Osteoporos Int 20:695-702

20. Salaffi F, Cimmino MA, Malavolta N, Caroti M, Di Matteo L, Scendoni P, Grassi W (2007) The burden of prevalent fractures on health-related quality of life in postmenopausal women with osteoporosis: the IMOF study. J Rheumatol 34:1551-1560

21. Papaioannou A, Kennedy CC, Ioannidis G, Brown JP, Pathak A, Hanley DA, Josse RG, Sebaldt RJ, Olszynski WP, Tenenhouse A, Murray TM, Petrie A, Goldsmith CH, Adachi JD (2006) Determinants of health-related quality of life in women with vertebral fractures. Osteoporos Int 17:355-363

22. Iwamoto J, Makita K, Sato Y, Takeda T, Matsumoto H (2010) Alendronate is more effective than elcatonin in improving pain and quality of life in postmenopausal women with osteoporosis. Osteoporos Int 22:2735-2742

23. Kawate H, Ohnaka K, Adachi M, Kono S, Ikematsu H, Matsuo H, Higuchi K, Takayama T, Takayanagi R (2010) Alendronate improves QOL of postmenopausal women with osteoporosis. Clin Interv Aging 5:123-131

24. Kushida K, Fukunaga M, Kishimoto H, Shiraki M, Itabashi A, Inoue T, Kaneda K, Morii H, Nawata H, Yamamoto K, Ohashi Y, Orimo H (2004) A comparison of incidences of vertebral fracture in Japanese patients with involutional osteoporosis treated with risedronate and etidronate: a randomized, double-masked trial. J Bone Miner Metab 22:469-478

25. Yoh K, Tanaka K, Ishikawa A, Ishibashi T, Uchino Y, Sato Y, Tobinaga M, Hasegawa N, Kamae S, Yoshizawa M (2005) Health-related quality of life (HRQOL) in Japanese osteoporotic patients and its improvement by elcatonin treatment. J Bone Miner Metab 23:167-173

26. Maugeri D, Russo E, Luca S, Leotta C, Mamazza G, Sorace R, Rizzotto M, Manuele S, Fiore V, Taverna G, Castiglia B, Calitro M (2009) Changes of the quality-of-life under the treatment of severe senile osteoporosis with teriparatide. Arch Gerontol Geriatr 49:35-38 